Book reviews

\section{Abortion and the Sanctity of Human Life: a philosophical approach}

\section{Baruch Brody}

Massacheusetts Institute of

Technology 1976. $152 \mathrm{pp}$.

This volume's subtitle 'A philosophical approach' is more than justified. This material arose from a programme on 'Contemporary Moral Issues' at MIT. It is a logical rigorous step-by-step examination of the issues. Abortion as selfdefence, the woman's right to her body, abortion for the sake of the child, abortion and the law, the definition of a 'living human being', and the responsibilities of society, are all dissected.

Some popular arguments are destroyed with devastating efficiency. For instance, he discusses the 'principle' that when the citizens of a society strongly disagree about the rightness or wrongness of a given action, and a considerable number think that such an action is right (or at least permissible), then it is wrong (or inappropriate) for that society to prohibit that action by law, even if the majority of citizens believe such an action to be wrong. Then he invites us to consider this principle in a society in which a significant number of citizens think that it is morally permissible, and even perhaps obligatory, to kill Blacks or Jews, for example because they are seen as being something less than fully human!

Again he considers the question of the definition of 'human being'. If no such phrase existed in the English language there could be no question of whether the fetus is part of its denotation. But that would not mean that the question we raise about the humanity of the fetus would not exist. It would still be a real and serious question. So our question is not about the denotation of that term and cannot be resolved by some linguistic definition.
Few of those involved in medicine will find Brody's arguments acceptable even when the logic appears impeccable. He maintains for instance that 'the obligation not to take a life is clearly of higher priority than the obligation to save lives'. Brody discusses the rectitude of taking one life in order to save two, and then by a series of steps alters the examples until more and more lives could be saved by sacrificing one. Even so he will never grant that such a sacrifice is justified. 'To be sure, I shall have failed to save their lives, but in those circumstances I am not obliged to do so, and my failing to do so involves no unjust violation of my moral obligations to them'.

Although our author claims to feel a keen empathy with women facing burdensome pregnancies he refuses to accept that abortion is ever justified; except perhaps where the embryo would succumb very shortly in any case and the woman's life can be saved by the procedure. He believes that most "but perhaps not all' cases can be alleviated by medical care, financial assistance, family therapy and day-care services: but goes on to prove that society is under no obligation to provide these.

Brody does not deal with medical matters, where he does stray into embryological detail in the case of twinning, he is in error.

Those of us who attempt to resist the flood towards automatic unthinking abortion will feel our case weakened by such remorseless logic reaching such unfeeling and unworkable conclusions. The book is heavy going, it is doubtful if the clinician will feel the effort was justified.

REX GARDNER

\section{Some Ethical issues in Family Planning}

Fred T. Sai

International Planned Parenthood

Federation 1976. 36 pp. 85p.
This booklet explains the reasoning behind the work of the International Planned Parenthood Federation, and counters the commonest arguments against this activity, especially that family planning is being foisted on the third world as a form of genocide. It spells out basic ideas eg 'It is very difficult to help raise the status of women in any society if they an: not at the same time given information on and the means to regulate their fertility.' Again, it defends the pill despite its risks. 'It has been calculated that for every death occurring because of the use of contraceptives in a developed country (USA) five would occur if the same population had not been using contraceptives'.

Sai, however, fails to discuss the morals underlying the practices he advocates. In fact, he appear to consider that none are involved apart from the need to bear in mind the social and cultural norms of the particular country. Perhaps this is considered inevitable in a work of a global organisation. There are, however, places where a bias shows through. He writes, ‘ . . the male. In his youth he would need a contraceptive for occasional use which is effective and safe'. Many of us refuse to accept the words I have italicised. As recently as 1965 Schofield showed that two thirds of men at eighteen had not found this to be a need. Constantly reiterated bland assumptions of this type help to change the climate towards establishing such a 'need'. Similarly Sai rightly explains the unwisdom of giving hormonal contraceptives to girls for the first two years after the menarche. On balance it would probably be the most scientifically humane approach to advise youngsters during this early period, and their parents, that however else attitudes are changing, chastity still has value at this early period of life!

Those wishing to read a brief review of the arguments in favour

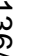

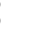

,
(n) 